\title{
Nitric Acid Reduction On 316L Stainless Steel Under Conditions Representative Of Reprocessing
}

\author{
R. C. Woodhouse ${ }^{\mathrm{a}}$, C. Boxall ${ }^{\mathrm{a}}$, R. J. Wilbraham ${ }^{\mathrm{a}}$ \\ ${ }^{a}$ Department of Engineering, Lancaster University, Lancaster, LA1 4YR
}

\begin{abstract}
Steels comprise the largest class of metal-based materials encountered on nuclear sites. An understanding of how process steels interact with $\mathrm{HNO}_{3}$ in spent fuel treatment plant environments is required to enable informed decisions to be made about the design and effective application of different steel types within nuclear environments. Stainless steels readily passivate in nitric acid. However, increasing the oxidising power of the media can lead to passive film dissolution, resulting in rapid transpassive corrosion. The corrosion of steels in nitric acid is further complicated by the autocatalytic reduction of $\mathrm{HNO}_{3}$ to aqueous $\mathrm{HNO}_{2}$ which attacks the steel surface. This paper describes the effect of this behaviour on process steels in stagnant and/or flowing conditions using electrochemical and microgravimetric based methods. We describe linear sweep voltammetry studies performed on a 316L stainless steel rotating disk electrodes in varying concentrations of nitric acid and rotation speeds and provide a qualitative interpretation of the results and what these imply about the mechanism of $\mathrm{HNO}_{3}$ reduction. These findings will be used in follow on studies to determine the kinetic parameters of the nitric acid reduction reaction at the surface of 316L stainless steel.
\end{abstract}

\section{Introduction}

Reprocessing of spent nuclear fuel is an important step in closed nuclear fuel cycles. Reprocessed uranium and plutonium may be used in uranium oxide, mixed oxide (MOX) or breeder reactors, recycling the bulk of the spent fuel material and reducing waste output significantly (1). In the UK, spent nuclear fuel is reprocessed at the THORP facility at Sellafield, Cumbria, using the Plutonium URanium EXtraction process (PUREX). The initial step in this process is the dissolution of spent fuel rods in high concentration nitric acid, $\sim 30 \%$ wt. $(2,3)$. The dissolved $U$ and $\mathrm{Pu}$ are subsequently controllably separated into either an aqueous $\mathrm{HNO}_{3}$ stream or a non-aqueous tri-n-butyl phosphate (TBP) and odourless kerosene (OK) stream. As a result of dilution, and also dissolved fission product/minor actinide induced radiolysis of $\mathrm{HNO}_{3}$, the concentration of $\mathrm{HNO}_{3}$ in the aqueous stream may vary through the PUREX flowsheet, to a minimum of $\sim 4 \%$ wt. (2-4).

Structurally, austenitic stainless steels are used in reprocessing pipework and tanks due to their ability to form thin, nm scale, iron/chromium protective oxide films in 
response to highly oxidising conditions, leading to passivation of the steel surface and consequent high corrosion resistance.

Interestingly the steel may also autocatalytically interact with the $\mathrm{HNO}_{3}$ resulting in a variety of nitrogen-oxygen based reduction products. This $\mathrm{HNO}_{3}$ reduction process has been previously studied on Platinum and on 304L stainless steels in nitric acid condensates (5). For concentrations of 1 to $10 \mathrm{~mol} \mathrm{dm}^{-3} \mathrm{HNO}_{3}$ two different mechanisms of nitric acid reduction have been proposed by Vetter and Schmid (6-8; 9-13). Vetter (68) describes the autocatalytic reduction of $\mathrm{HNO}_{3}$ as a heterogeneous process, where the chemical regeneration of $\mathrm{NO}_{2}$ (electroactive species) occurs at the electrode surface. In this case stirring would be expected to have no influence on the current density due to the adsorbed nature of the electroactive species. Schmid [9-13] describes the reduction of $\mathrm{HNO}_{3}$ as an autocatalytic process moderated by the chemical regeneration of $\mathrm{NO}^{+}$ (electroactive species).

There is currently broad consensus in the literature that Schmid obtains which at a top level, may be expressed as:

$$
\begin{gathered}
\mathrm{HNO}_{2}+\mathrm{H}^{+}+\mathrm{e}^{-} \rightarrow \mathrm{NO}_{\mathrm{ads}}+\mathrm{H}_{2} \mathrm{O} \\
2 \mathrm{NO}+\mathrm{HNO}_{3} \rightarrow 3 \mathrm{HNO}_{2}
\end{gathered}
$$

Equation [2] has been shown to be slow at $\left[\mathrm{HNO}_{3}\right]<6 \mathrm{~mol} \mathrm{dm}^{-3}$ (14), with only equation [1] occurring with appreciable rate over that concentration range. At $\left[\mathrm{HNO}_{3}\right]>6$ mol dm${ }^{-3}$. as a result of increased $\left[\mathrm{HNO}_{2}\right]$ and increased thermodynamic stability of the intermediates (specifically $\mathrm{NO}_{2}$ (14), see below), Equation [2] proceeds fast enough to produce, in concert with equation [1], an autocatalytic cycle for $\mathrm{HNO}_{2}$ reduction and regeneration, leading ultimately to enhanced rates of $\mathrm{HNO}_{3}$ reduction on the electrode surface.

As mentioned above, this top level reaction is broadly accepted in the literature. However, there are two distinct schools of thought as to the mechanism of Equation [2]. One view, extensively studied by Balbaud (15) and Fauvet (14) is based on the reaction of a series of surface bound intermediates.

$$
\begin{gathered}
\mathrm{HNO}_{3}+\mathrm{NO}_{\text {ads }} \rightarrow \mathrm{HNO}_{2}+\mathrm{NO}_{2 \text { ads }} \\
2 \mathrm{NO}_{2 \text { ads }} \rightarrow \mathrm{HNO}_{3}+\mathrm{HNO}_{2}
\end{gathered}
$$

The other, most recently described by Lange (16) and essentially revisiting some early studies by Carta \& Pigford (17) and Abel and Schmid (18-20), suggests the following solution phase mechanism:

$$
\begin{gathered}
\mathrm{HNO}_{3}+\mathrm{HNO}_{2} \rightarrow 2 \mathrm{NO}_{2} \\
\mathrm{NO}_{2}+\mathrm{NO} \rightarrow 2 \mathrm{HNO}_{2}
\end{gathered}
$$


This latter mechanism may be facilitated by NO desorption, as a result of high NO generation fluxes that might obtain from Equation [1] under autocatalytic acceleration by Equation [2].

The mechanism of Equations [3] and [4] is surface based, whilst that of Equations [5] and [6] is solution based. One objective of the current study is to resolve which is occurring at high nitric acid concentrations on 316L stainless steel (SS). Whilst the electrochemical reduction of $\mathrm{HNO}_{3}$ is otherwise well understood, the effect of nitric acid concentrations $>5 \%$ wt., typical of those found in aqueous reprocessing streams, on nuclear process steel, such as 316L SS, has hitherto not been extensively explored and this comprises the second objective of this study.

Thus, here we investigate the electrochemical behaviour of 316L SS stainless steel as a function of nitric acid concentration. In order to determine the region of electrochemical passivity of 316L SS, we first describe baseline polarisation studies on 316L SS as a function of nitric acid concentration in the range 5-35\% wt. This is followed by an electrochemical quartz crystal microbalance (EQCM) study of the in situ growth of process steel passive oxide layers, again as a function of nitric acid concentration. It is possible that the growth of a passive oxide on the 316L SS will inhibit the nitric acid reduction reaction, due to the oxide restricting access to sites on the steel surface that would allow the reduction of reaction to occur. Finally, in order to obtain insight into whether the reduction of $\mathrm{HNO}_{3}$ at 316 LS is a heterogeneous surface or homogenous solution process, we also describe rotating disk electrode studies on 316L SS as a function of $\left[\mathrm{HNO}_{3}\right]$.

\section{Experimental}

\section{$\underline{\text { Materials }}$}

All chemicals were of AnalaR grade or better and supplied by Sigma-Aldrich Ltd. (Gillingham, Dorset, UK), the nitric acid being ACS reagent $70 \%$ wt. The $10 \mathrm{~mm}$ diameter stainless steel 316L bars, from which working electrodes were fabricated, were purchased from Advent Research Materials (Eynsham, Oxford, UK). EQCM piezoelectodes comprised of polished stainless steel 2343 (similar composition to 316L SS) were purchased from Q-sense (Biolin Scientific, Coventry, UK). The piezoelectrode crystals were quartz, AT cut, with a resonant frequency of $5 \mathrm{MHz}$ and a $25^{\circ} \mathrm{C}$ temperature profile.

All nitric acid solutions were prepared using doubly deionised water. Double deionised water was prepared using a Direct-Q 3 UV Millipore water purification system (Millipore, Watford, UK) to a resistivity of $18.2 \mathrm{M} \Omega . \mathrm{cm}$. Unless otherwise noted, electrolyte solutions were de-aerated by bubbling high purity nitrogen (BOC, UK) before all electrochemical measurements.

\section{L SS Electrode Preparation}

The 10mm diameter stainless steel 316L bars were sliced and mounted on a brass head using silver loaded epoxy. This assembly was then placed in a cylindrical shape mould and sealed in epoxy resin in order to produce a suitable working electrode. Pre-treatment 
of the resultant working electrode consisted of polishing on 1200 grade emery paper, 6 and 1 micron diamond paste, before degreasing in acetone and rinsing with deionised water.

\section{Linear Sweep Voltammetry of 316L SS in Nitric Acid}

Linear sweep voltammetric (LSV) studies on the stainless steel (316L) electrodes immersed in nitric acid were measured using an Autolab potentiostat PGSTAT100. A three electrode cell was employed using a platinum mesh counter with a saturated calomel electrode (SCE) as the reference electrode. LSV measurements on 316L SS in the presence of increasing concentrations of nitric acid were performed in $100 \mathrm{~mL}$ solutions of 5\% wt. - 35\% wt. nitric acid. Before the LSV studies, the 316L SS electrodes were left to calibrate for one hour, to allow for equilibration of the open circuit potential. After $1 \mathrm{~h}$ at open circuit potential $\left(\mathrm{E}_{\mathrm{oc}}\right)$, measurements of polarisation curves were made. During the LSV studies the potential was run from $-0.5 \mathrm{~V}$ to $1.5 \mathrm{~V}$, at a scan rate of $0.1 \mathrm{~V} / \mathrm{min}$.

\section{$\underline{\text { Microgravimetric Potential Step and Polarisation Studies of SS2343 in Nitric Acid }}$}

The EQCM is a well-established method for the measurement of small changes in mass due to reactions at the electrode-solution interface. Importantly, the EQCM has also been used to investigate passive film growth on metallic surfaces (21-26). It provides in situ information of mass change at the electrode surface and a time resolution sufficient to provide real time growth curves of the passive film, as established by Olsson et al (27). This makes microgravimetry useful in the study of the dynamic responses of passive metals and alloys to redox changes in the aqueous environment and particularly, applied potential.

A detailed description of QCM theory may be found in various texts (28-31). Assuming mass is rigidly bound, the measured shift in the resonant frequency is converted to a mass change via the Sauerbrey equation, Equation [7]

$$
\Delta f=-\mathrm{C}_{f} \Delta m
$$

Where $\Delta f$ is the change in resonant frequency $(\mathrm{Hz}), \Delta m$ is the mass change $(\mathrm{g})$ and $C_{f}$ is the sensitivity constant. The value of $\mathrm{C}_{f}$ can be determined from electrochemical deposition and dissolution of copper via cyclic voltammetry $(32,33)$ we have found it to be $0.059 \mathrm{~Hz}\left(\mathrm{ng} \mathrm{cm}^{-2}\right)$, which is in excellent agreement with a theoretical value of 0.056 $\mathrm{Hz}\left(\mathrm{ng} \mathrm{cm}{ }^{-2}\right.$ ) quoted by the manufacturer (Q-sense, Biolin Scientific, Manchester, UK).

EQCM experiments were carried out using a quartz crystal microbalance from Maxtek (5980 Lakeshore Drive, Cypress, CA, USA) and a Q-Sense open module (Gothenburg, Sweden) with a combined Autolab PGSTAT20 potentiostat from Windsor Scientific Ltd. (Slough, UK). Current and mass-response profiles were always recorded simultaneously. Polarisation and potential step measurements were performed in $1.5 \mathrm{~mL}\left(1.5 \mathrm{~cm}^{3}\right)$ solutions of $5 \%$ wt. $-35 \%$ wt. $\mathrm{HNO}_{3}$

$\underline{\text { Rotating Disk Electrode (RDE) Studies }}$ 
RDE studies on process stainless steel (316L) electrodes were set up akin to the polarisation studies. First, in order to condition the electrode, a reverse polarization scan was performed from $0.75 \mathrm{~V}$ down to a potential of $0.25 \mathrm{~V}$. Then the potential was then held whilst the rotation of the electrode was varied from 100-3000rpm and the current measured. At each rotation speed the current was allowed to stabilize for 5 minutes before a reading was taken.

\section{Results and Discussion}

\section{$\underline{\text { Polarisation Studies }}$}

Figure 1(a) shows potentiodynamic polarisation curves for 316L stainless steel electrodes recorded in $\mathrm{HNO}_{3}$ concentrations from 5-35\% $\left(1.13-7.89 \mathrm{~mol} \mathrm{dm}{ }^{-3}\right)$ over the potential range $-0.5 \mathrm{~V}$ to $1.5 \mathrm{~V}$. This range of concentrations was chosen because $\left[\mathrm{HNO}_{3}\right]$ $\leq 15 \%$ ( $\leq 3.38 \mathrm{~mol} \mathrm{dm}^{-3}$ ) is representative of concentration regimes encountered in typical nuclear plant reprocessing streams, whilst $35 \%\left(7.89 \mathrm{~mol} \mathrm{dm}^{-3}\right)\left[\mathrm{HNO}_{3}\right]$ is representative of conditions encountered in highly active liquid evaporators.
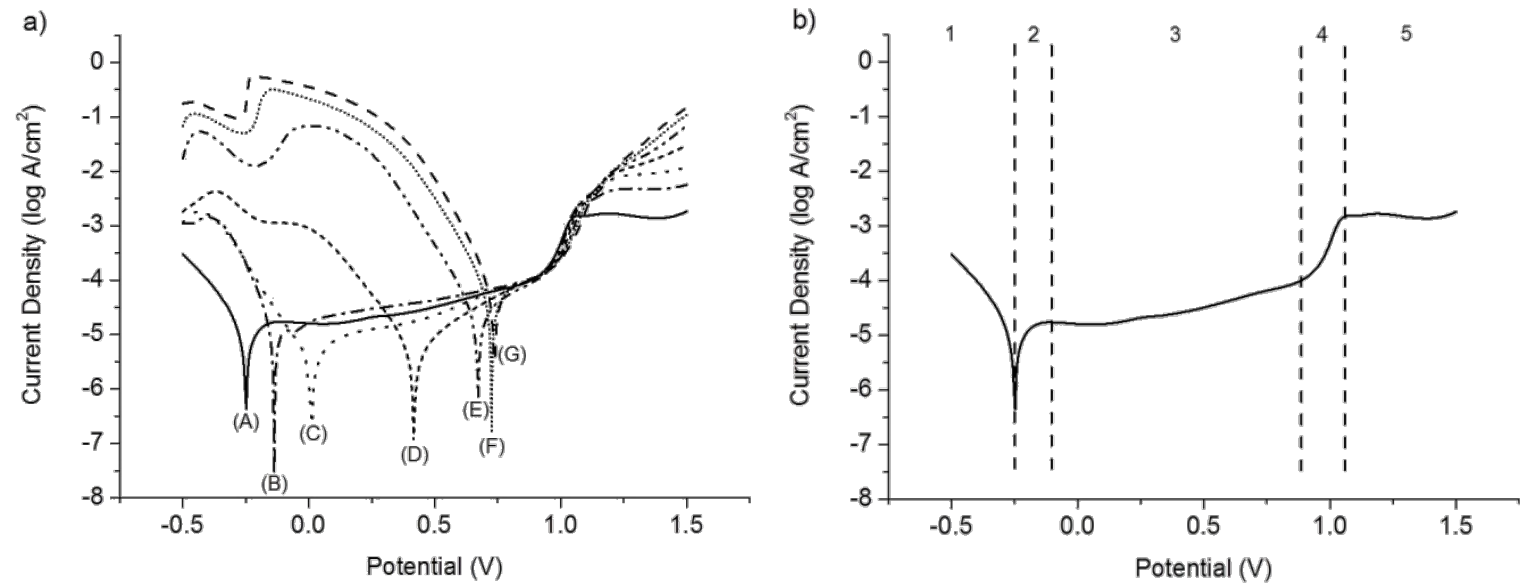

Figure 1. Potentiodynamic polarisation plots of SS316L in 5\%-35\% (A-G) $\mathrm{HNO}_{3}$ at room temperature $\left(20 \pm 2^{\circ} \mathrm{C}\right.$ ). Plots were measured in the potential range $-0.5 \mathrm{~V}$ to $1.5 \mathrm{~V}$ (sweep rate, $10 \mathrm{mVs}^{-1}$ ), (a) Shows the polarisation curves for 5\%-35\% $\mathrm{HNO}_{3}$. b) Potentiodynamic polarisation plot for $5 \% \mathrm{HNO}_{3}$, zones 1-5 are describes in the text.

From Figure 1(a) it can be observed that at all $\mathrm{HNO}_{3}$ concentrations studied, five distinct regions may be identified which, for the sake of illustrative clarity, are indicated on the annotated curve recorded at $5 \%\left(1.13 \mathrm{~mol} \mathrm{dm}^{-3}\right)$ nitric acid, Figure 1(b). These regions correspond to (1) active dissolution, (2) onset of passivation, (3) passivity, (4) transpassive dissolution and (5) secondary passivation/oxygen evolution (34). Returning to Figure $1 \mathrm{a}$, it can be seen that there is a shift in the corrosion potential $\left(\mathrm{E}_{\mathrm{corr}}\right)$ between 15 and $20 \%$ (3.38 and $4.51 \mathrm{~mol} \mathrm{dm}^{-3}$ ) $\mathrm{HNO}_{3}$. At $\left[\mathrm{HNO}_{3}\right] \leq 15 \%$ the steel begins to passivate in the region of -0.2 to $-0.1 \mathrm{~V}$, whereas at $\left[\mathrm{HNO}_{3}\right] \geq 20 \%$ passivation of the surface does not occur until a potential of $\geq 0.5 \mathrm{~V}$ is reached. This shift results in a much narrower passive region at $\left[\mathrm{HNO}_{3}\right] \geq 20 \%$, behaviour that may be explained as follows. The corrosion potential of the 316L steel surface in the presence of $\mathrm{HNO}_{3}$ is controlled by the concentration of $\mathrm{HNO}_{2}$ available to interact with the steel surface, as shown by 
Equation [1] (14). At low concentrations of $\mathrm{HNO}_{3}(\leq 15 \%)$ the autocatalytic regeneration of $\mathrm{HNO}_{2}$ is slow (as described above). However, at high $\mathrm{HNO}_{3}$ concentrations (>15\%) the regeneration of $\mathrm{HNO}_{2}$ is fast, due both to the increased availability of $\mathrm{HNO}_{3}$ in Equation [2] to the stability of $\mathrm{NO}_{2}$, either in solution or adsorbed at the metal surface. Thus, charge transfer at the steel surface through Equation [1] is not limited by the concentration of $\mathrm{HNO}_{2}$, resulting in an increase in the observed corrosion potential and decrease in the window of passivity.

$\underline{E}_{\text {corr_and }} \mathrm{I}_{\text {corr }}$ Analysis. Corrosion potential $\left(\mathrm{E}_{\text {corr }}\right)$ and corrosion current density ( $\left.\mathrm{I}_{\text {corr }}\right)$ were calculated using Tafel extrapolation of the linear segments of the measured potential-current density curves of Figure $1 \mathrm{a}$, in the vicinity of $\mathrm{E}_{\text {corr }}$. As nitric acid is an oxidising agent, $\mathrm{E}_{\mathrm{corr}}$ and $\mathrm{I}_{\text {corr }}$ are dependent on the autocatalytic reduction of nitric acid and both are known to increase with higher autocatalytic contribution via equation [1] and [2] to the global reduction of nitric acid (35). Figure 2a shows calculated $\mathrm{E}_{\text {corr }}$ values obtained at $5-35 \%\left[\mathrm{HNO}_{3}\right]$. From Figure $2 \mathrm{a}$ it can be seen that $\mathrm{E}_{\text {corr }}$ has sigmoidal dependency on $\mathrm{HNO}_{3}$ concentration with $\mathrm{E}_{\text {corr }}$ increasing in the range 10-25\% (2.26-5.53 mol dm$\left.{ }^{-3}\right)\left[\mathrm{HNO}_{3}\right]$, before plateauing at $\left[\mathrm{HNO}_{3}\right] \geq 25 \%$.
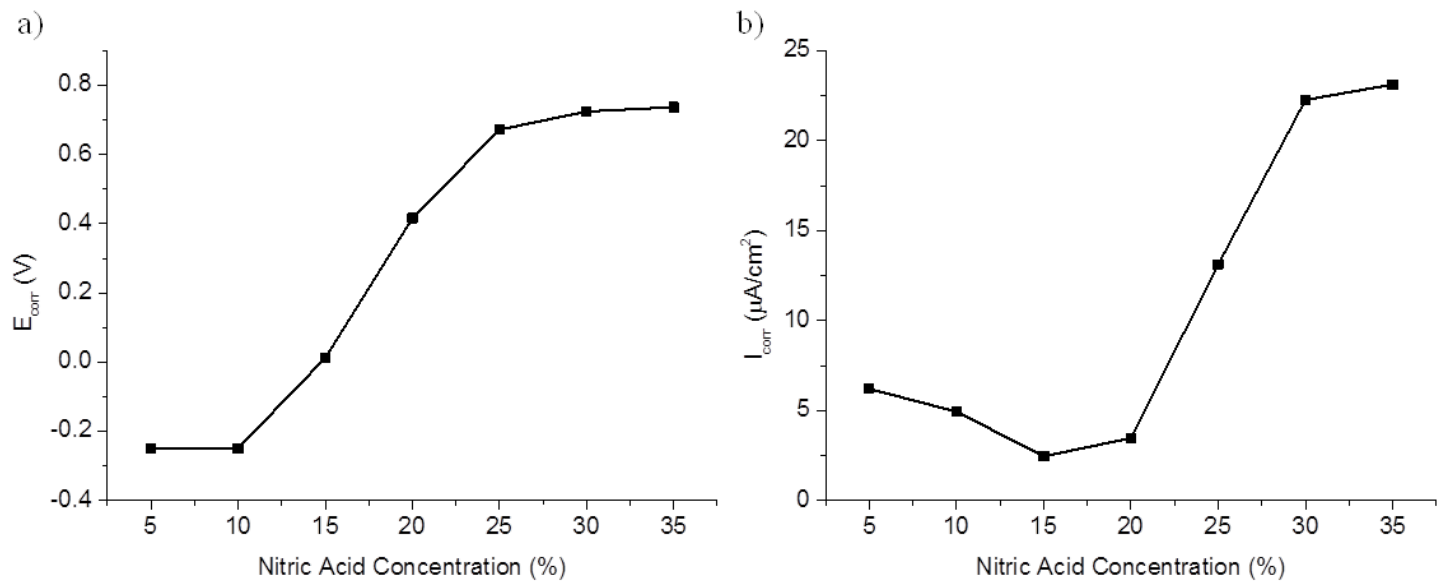

Figure 2. a) Corrosion potential, $\mathrm{E}_{\text {corr, }}$ values vs $\left[\mathrm{HNO}_{3}\right]$ b) Corrosion current density, $\mathrm{I}_{\text {corr }}$, values vs. $\left[\mathrm{HNO}_{3}\right]$ calculated from Figure 1a for 316L SS in 5-35\% nitric acid.

Figure $2 \mathrm{~b}$ shows the $\mathrm{I}_{\text {corr }}$ values for $5-35 \%\left[\mathrm{HNO}_{3}\right]$. $\mathrm{I}_{\text {corr }}$ values are not greatly affected by increasing $\left[\mathrm{HNO}_{3}\right]$ at $\left[\mathrm{HNO}_{3}\right]<20 \%$. At $\left[\mathrm{HNO}_{3}\right] \geq 20 \%\left(4.51 \mathrm{~mol} \mathrm{dm}^{-3}\right) \mathrm{I}_{\text {corr }}$ increases indicating that the passive oxide film on the surface of the steel is degrading resulting in an increase in the corrosion rate. 


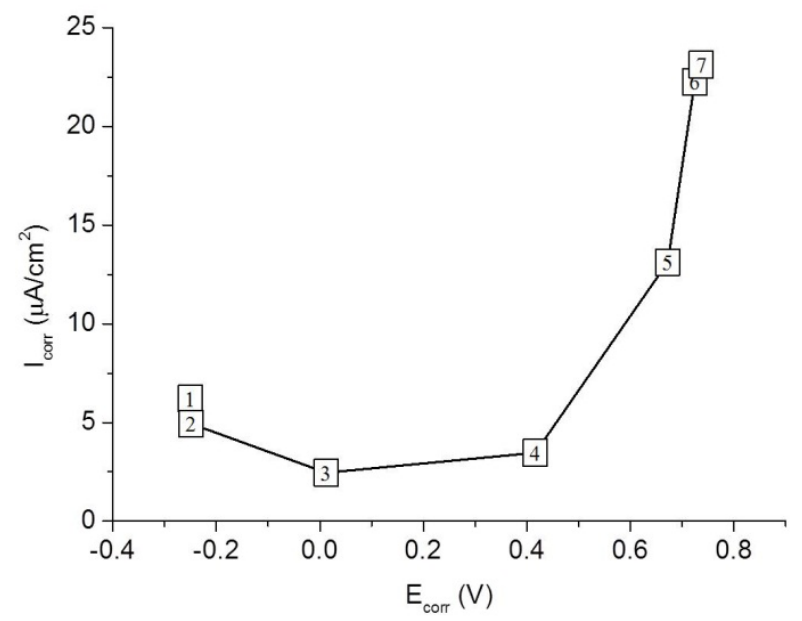

Figure 3. $E_{\text {corr }}$ Vs. $I_{\text {corr }}$ calculated from Figure 1a for 316L SS in 5-35\% (1-7 respectively) nitric acid.

Figure 3 shows $\mathrm{E}_{\text {corr }}$ Vs. $\mathrm{I}_{\text {corr }}$ calculated from LSV results in Figure 1a. It is interesting to note that at $\geq 20 \%\left(4.51 \mathrm{~mol} \mathrm{dm}^{-3}\right)$ where $E_{\text {corr }}$ equals $0.4 \mathrm{~V}$, $\mathrm{I}_{\text {corr }}$ increases with increasing concentration of nitric acid. This indicates that at $\sim 20 \% \mathrm{HNO}_{3} \mathrm{E}_{\text {corr }}$ begins to move into the transpassive region for 316L SS; dissolution of the passive film is occurring and the corrosion rate is increasing. This point will be discussed further in relation to the EQCM results.

\section{$\underline{\text { Potential Step Studies }}$}

Using the EQCM, chronoamperometric-microgravimetric measurements were made by means of a potential 'staircase' experiment in which the potential was stepped by $0.15 \mathrm{~V}$ from an initial value of $-0.2 \mathrm{~V}$ to $1.15 \mathrm{~V}$. At each step on the 'staircase' the potential was held for 1 hour and the resultant current transient and change in electrode mass was recorded.

Figure 4 shows the time dependence of the changes in electrode mass (as determined by the use of the Sauerbrey equation (36)) that occur in response to the potential 'staircase' as a function of $\mathrm{HNO}_{3}$ concentration, from $\left[\mathrm{HNO}_{3}\right]$ of $5 \%$ (Figure 4A) to 35\% (Figure 4G). At lower concentrations of $\mathrm{HNO}_{3}(\leq 15 \%)$, mass gain occurs rapidly at a potential of $-0.2 \mathrm{~V}$ due to the formation of the $\mathrm{Cr} / \mathrm{Fe}$ oxide passive film. This mass gain slows between $0.25 \mathrm{~V}$ and $0.4 \mathrm{~V}$, corresponding to the region where it has been suggested that $\mathrm{Cr}$ oxidation from $\mathrm{Cr}(\mathrm{III})$ to $\mathrm{Cr}(\mathrm{VI})$ occurs (37). $\mathrm{Cr}(\mathrm{VI})$ is more soluble and is therefore slowly released from the electrode surface (passive corrosion), leading to a lower rate of mass increase from the consequently decreased passive oxide formation. At higher potentials, $\sim 0.7 \mathrm{~V}$ to $0.85 \mathrm{~V}$, a mass decrease is observed, most likely due to the rapid dissolution of the high valency $\mathrm{Cr}(\mathrm{VI})$ that precedes the onset of transpassive dissolution (38). At $1 \mathrm{~V}$ transpassive dissolution leads to a renewed strong decrease in mass, almost certainly associated with the onset of transpassive dissolution (39). 


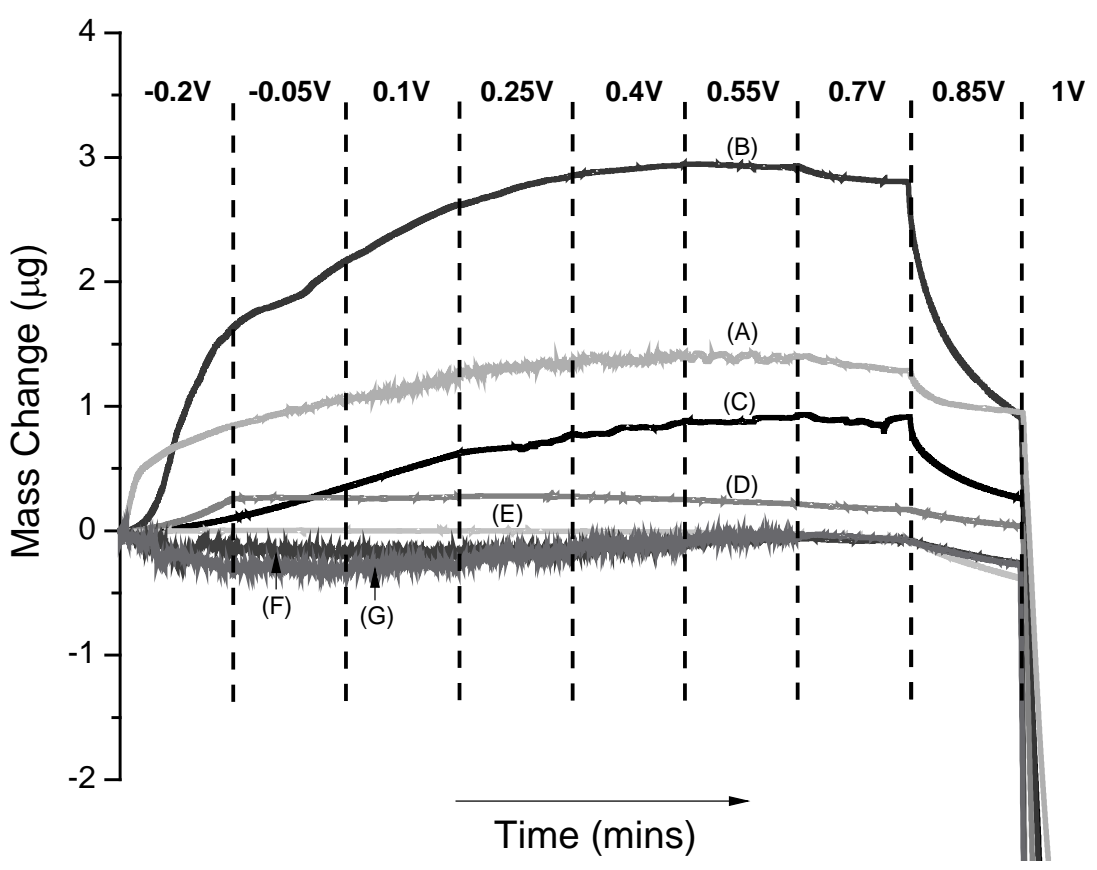

Figure 4. Mass change of SS2343 as a function of time during potential step experiments in 5-35\% (A-G respectively) $\mathrm{HNO}_{3}$. Polarisation conditions: Start potential $=-0.2 \mathrm{~V}$, end potential $=1 \mathrm{~V}$, potential step $=0.15 \mathrm{~V}$, time between steps $=45$ mins.

At $\left[\mathrm{HNO}_{3}\right] \geq 20 \%$ the pattern of mass change alters. This is in agreement with the polarisation experiment results of Figure 2, the $\mathrm{I}_{\text {corr }}$ results of Figure $2 \mathrm{~b}$ and also the $\mathrm{E}_{\text {corr }}$ vs $\mathrm{I}_{\text {corr }}$ results in Figure 3, wherein changes in electrode behaviour are observed between $15 \%$ and $20 \%\left[\mathrm{HNO}_{3}\right]$ as described previously. Due to the autocatalytic nature of $\mathrm{HNO}_{3}$ driven oxidation processes on steel at higher $\left[\mathrm{HNO}_{3}\right]$, the active-passive transition shifts to a higher potential, $\geq 0.4 \mathrm{~V}$, at $\left[\mathrm{HNO}_{3}\right]$ of $\geq 20 \%$. From figure 4 it can be seen that this narrowing of the passive region leads to a mass decrease at lower potentials for $\left[\mathrm{HNO}_{3}\right]$ $\geq 20 \%$, most likely due to the oxidation of $\mathrm{Fe}$ and $\mathrm{Cr}$ by $\mathrm{HNO}_{2}$ to higher oxidation states competing effectively with passive film formation, thereby increasing the corrosion rate. Interestingly, there are also small increases in mass at the higher potentials, consistent with the displacement of onset of passive film formation that would be expected as $E_{\text {corr }}$ increases with $\left[\mathrm{HNO}_{3}\right]$. The smaller size of this change compared to that obtained at lower nitric concentrations indicates either that: 1) a much thinner film is formed or 2) the film is not fully formed and only partially passive in character. One consistent pattern of behaviour is the rapid decrease in mass at $1 \mathrm{~V}$, corresponding to the passivetranspassive transition. This does not appear to be affected by the increase in $\mathrm{HNO}_{3}$ concentration, again most likely due to this being associated with the onset of transpassive dissolution.

\section{$\underline{\text { Rotating Disk Electrode Studies }}$}

In order to investigate the effect of stirring on the $\mathrm{HNO}_{3}$ reduction process, $\mathrm{RDE}$ studies were performed using 316L SS disk electrodes. Importantly, oxide formation is likely to inhibit the nitric acid reduction on the steel surfaces. In order to remove this inhibition as a factor in our rotation studies, the polarisation curves were first run in reverse, scanning cathodically from the transpassive region. Figure 5 shows a linear 
potential scan of $316 \mathrm{~L}$ SS in a $5 \% \mathrm{HNO}_{3}$ solution. A current is observed in the 0.1 to $0.4 \mathrm{~V}$ region. This has been attributed to the surface electrode reaction from Equation [1] where $\mathrm{HNO}_{2}$ is reduced at the electrode surface to, in the first instance, NO. Maximum current density is observed at $0.25 \mathrm{~V}$, consequently this was selected as the applied potential for all subsequent rotation speed studies. The decrease in reduction current at $\mathrm{E}$ $<0.25 \mathrm{~V}$ is attributed to the further reduction of $\mathrm{NO} / \mathrm{HNO}_{2}$ to $\mathrm{N}_{2} \mathrm{O}$ with a consequent impact on the autocatalysis facilitated by Equation 2 .

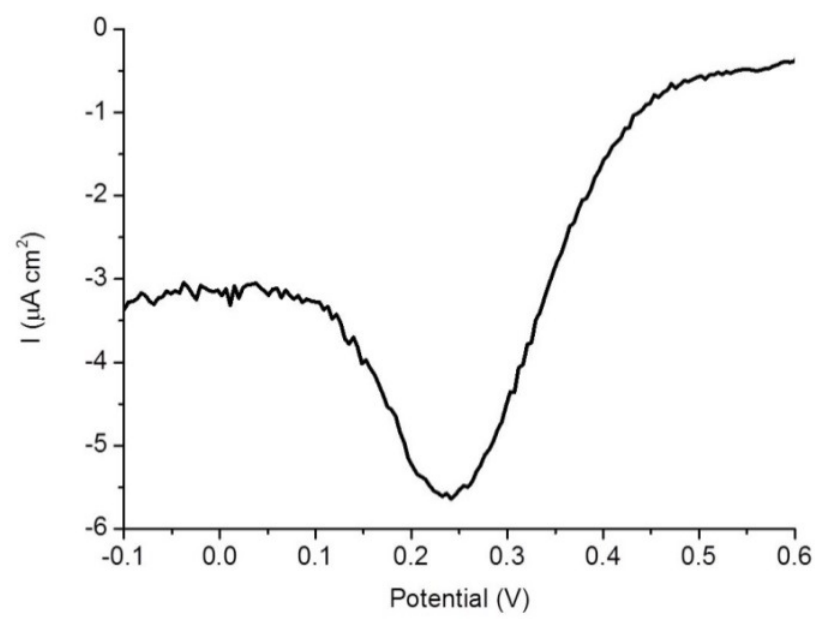

Figure 5. Polarisation curve showing a cathodic scan of 316L SS in 5\% nitric acid at a rate of $10 \mathrm{mVs}^{-1}$.

Figure 6 shows a plot of rotation speed vs. current density at $0.25 \mathrm{~V}$ in 5, 20 and $35 \%$ nitric acid. The results show that at the lower nitric acid concentrations of 5 and 20\%, current density is independent of rotation speed. This indicates that the net $\mathrm{HNO}_{3}$ reduction reaction of Equations [1] and [2] is mediated by electroactive species that are entirely adsorbed at the electrode surface. At 35\% nitric acid, the current decreases with increasing rotation speed, indicating that at least a proportion of the net $\mathrm{HNO}_{3}$ reduction is now being mediated by a mechanism making electroactive species (or precursor to some) in the bulk solution phase.

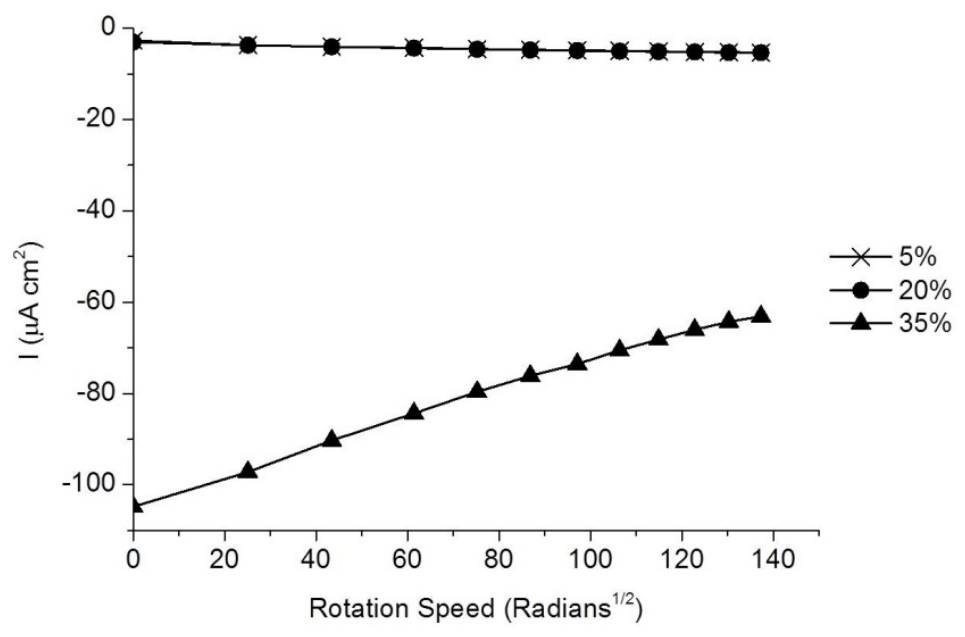


Figure 6. Rotation Speed vs Current Density at $0.25 \mathrm{~V} / \mathrm{SCE}$ as a function of $\mathrm{HNO}_{3}$ concentration.

According to Abel \& Schmid (10-13) and supported by, inter alia, Balbaud (15), Fauvet (14) and Lange (16) the electroactive species in this reaction is believed to be $\mathrm{HNO}_{2}$ as per Equation [2]. At 5 and 20\% (1.13 and $\left.4.51 \mathrm{~mol} \mathrm{dm}^{-3}\right) \mathrm{HNO}_{3}$, the observed reduction current shows a slight current increase with increasing rotation speed. This is most likely due to the increase flux of nitric acid to the surface of the steel, allowing it to react with the surface adsorbed NO via Equation [3]. Stirring of the electrode has no influence because the reaction is following the Balbaud (15) and Fauvet (14) reaction mechanism of Equations [3] and [4], where the electroactive reaction intermediates, or their immediate precursors, are adsorbed at the electrode surface.

At 35\% (7.89 $\left.\mathrm{mol} \mathrm{dm}^{-3}\right)$ the rotation of the electrode leads to a decrease in the current density. This inverse dependence of the current density on rotation speed is consistent with the loss, due to the stirring, of a solution phase electrogenerated electroactive entity or electrogenerated solution phase precursor of an electroactive entity. This is most likely to be NO in accordance with Lange's (16) solution phase mechanism of Equation [5] and [6]. Here at high concentrations of $\mathrm{HNO}_{3}$, $\mathrm{NO}$ is rapidly produced at the electrode surface, the resultant excess of NO leading to its subsequent desorption. This desorption allows $\mathrm{NO}_{2}$, which is formed in solution in Equation [5], to react and regenerate electroactive species $\mathrm{HNO}_{2}$. This is supported by the solution based reaction mechanism supported by Lange (16) and consistent with chemistry originally suggested by Carta \& Pigford (17). The stirring of the solution would lead to the dispersal of NO into the bulk solution, preventing the regeneration of $\mathrm{HNO}_{2}$, thus, retarding the autocatalytic cycle and leading to a decrease in the current density. That the mechanism proposed by Balbaud (15) and Fauvet (14) may still occur in parallel at the electrode surface but more rapidly than at lower concentrations of nitric acid, due to the increased thermodynamic stability of $\mathrm{NO}_{2}$ at the lower $\mathrm{pH}$.

\section{Conclusions}

We have described the LSV and EQCM studies performed on 316L SS RDEs at varying concentrations of nitric acid and rotation speeds. The study led to the following conclusions.

The polarisation and EQCM results indicate a shift in electrochemical behaviour with increasing nitric acid concentration. RDE studies indicate two forms of Schmid's mechanism obtain on steels: 1) $\left[\mathrm{HNO}_{3}\right] \leq 20 \%$, the reaction of surface adsorbed intermediates such as $\mathrm{NO}$ and $\mathrm{NO}_{2}$ dominate (as proposed by Balbaud (14) and Fauvet (15)) and the associated reduction current then shows no dependence on electrode rotation speed. 2) at $\left[\mathrm{HNO}_{3}\right] \geq 20 \%$, the reaction of $\mathrm{NO}$ and $\mathrm{NO}_{2}$ intermediates in the bulk solution phase dominate (proposed by Lange (16) and Carta \& Pigford (17)) and the associated reduction current then decreases with increasing rotation speed.

The latter behaviour is important when considering stainless steel pipework within nuclear environments that contain high concentrations of $\mathrm{HNO}_{3}$. At higher concentrations any stagnation or reduction in the flow rate may lead to an increase in the autocatalytic 
reduction process of nitric acid which, in turn, will lead to an increase in the corrosion potential, moving towards transpassive behaviour. This will over time lead to intergranular corrosion and subsequent pipework failure. This knowledge will aid in determining conditions which may move stainless steels away from their passive domain, enabling decisions to be made to ensure the durability of the UK's spent fuel treatment plants.

Further work will involve numerical treatment of the RDE results obtained in this study, including Koutecky-Levich analysis (28). RDE studies for potentials either side of the $0.25 \mathrm{~V}$ peak shown in Figure 6 will also be required to further investigate influence of potential on the the kinetics of this nitric acid reduction mechanism at the stainless steel surface under concentrations representative of nuclear reprocessing.

\section{Acknowledgments}

We thank the Nuclear Decommissioning Authority (NDA) and Lloyd's Register Foundation (LRF). LRF, a UK registered charity and sole shareholder of Lloyd's Register Group Ltd, invests in science, engineering and technology for public benefit, worldwide.

\section{References}

1. P.D. Wilson, The Nuclear Fuel Cycle: From Ore to Waste, OUP Oxford (1996).

2. J.L. Robertson, Chapter 9 - Nuclear Fuel Reprocessing, in, NTEC (2011).

3. K.V. Hecke, P. Goethals, Research on Advanced Aqueous Reprocessing of Spent Nuclear Fuel : Literature Study, SCK•CEN (2006).

4. J.M. McKibben, Radiochim. Acta, 36, 3-15 (1984).

5. F. Balbaud, G. Sanchez, G. Santarini and G. Picard, Eur. J. Inorg. Chem. 2000(4) 665-674 (2000).

6. K. Vetter, Z. Phys. Chem. 194, 199-206 (1950).

7. K. Vetter, Z. Phys. Chem. 194, 284-296 (1950).

8. K. Vetter, Z. Elektrochem., Ber Bunsenges. physik. Chem. 63, 1189-1191 (1959).

9. G. Schmid, Z. Elektrochem., Ber. Bunsenges. physik. Chem. 63, 1192-1188 (1959).

10. G. Schmid, J. Delfs, Z. Elektrochem., Ber. Bunsenges. physik. Chem. 63, 11921197 (1959).

11. G. Schmid, Z. Elektrochem., Ber. Bunsenges. physik. Chem. 65, 531-534 (1961).

12. G. Schmid, G. Krichel, Z. Elektrochem., Ber. Bunsenges. physik. Chem. 68, 677688 (1964).

13. G. Schmid, M. A. Lobeck, Z. Elektrochem., Ber. Bunsenges. Chem. 73, 89-199 (1969).

14. P. Fauvet, F. Balbaud, R. Robin, Q.T. Tran, A. Mugnier, D. Espinoux, Journal of Nuclear Materials, 375, 52-64 (2008).

15. F. Balbaud, G. Sanchez, P. Fauvet et al. Corros. Sci., 42 (10), 1685-1707 (2000).

16. R. Lange, E. Maisonhaute, R. Robin, V. Vivier, Electrochem. Comm., 29, 25-28 (2013).

17. G. Carta, R. Pigford, Ind. Eng. Chem. Fundam., 329(6), 329-335 (1983).

18. E. Abel, H. Schmid, Z. Phys. Chem. 132, 56, 64 (1928a). 
19. E. Abel, H. Schmid, Z. Phys. Chem, 134, 279 (1928b).

20. E. Abel, H. Schmid, Z. Phys. Chem, 136, 153, 419 (1928c).

21. P. Schmutz, D. Landolt, Electrochim. Acta, 45, 899-911 (1999).

22. P. Schmutz, D. Landolt, Corros. Sci., 41, 2143-2163 (1999).

23. D. Hamm, C.O.A. Olsson, D. Landolt, Corros. Sci., 44, 1009-1025 (2002).

24. C.O.A. Olsson, D. Hamm, D. Landolt, J. Electrochem. Soc., 147, 2563-2571 (2000).

25. M. Itagaki, H. Nakazawa, K. Watanabe, K. Noda, Corros. Sci., 39, 901-911 (1997).

26. C.O.A. Olsson, D. Landolt, J. Electrochem. Soc., 148, B438-B449 (2001).

27. C.O.A. Olsson, D. Hamm, D. Landolt, J. Electrochem. Soc., 147, 4093-4102 (2000).

28. A. Bard, L. Faulkner, Electrochemical Methods: Fundementals and Applications, John Wiley \& Sons, New York (2001).

29. D.A. Buttry, Electroanal. Chem., pp. 1-85 (1991).

30. D.A. Buttry, in Electrochemical Interfaces: Modern Techniques for In-Situ Interface Characterisation, H.D. Abruna, Editor, VHC Publishers Inc., pp. 529566, (1991)

31. M.R. Deakin, D.A. Buttry, Anal. Chem., 61, 1147A-1154A, (2008).

32. C. Gabrielli, M. Keddam, R. Torresi, J. Electrochem. Soc. 138(9), 2657-2660 (1991).

33. G. L. Borges, K. K. Kanazawa, J. G. Gordan II, J, Electroanal. Chem. 364(1-2) 281-284 (1994).

34. M. Bojinov, I. Betova, R. Raicheff, J. Electroanal. Chem., 430, 169-178 (1997).

35. N. Padhy Role of Passivity and Surface Modification on the Corrosion Behaviour of AISI 304L Stainless Steel in Nitric Acid Medium, Homi Bhabha National Institute (HBNI) (2010).

36. M. Inc., RQCM: Research Quartz Crystal Microbalance; operation and service manual (2002).

37. C.O.A. Olsson, D. Landolt, Electrochim. Acta, 48, 1093-1104 (2003).

38. N. Padhy, R. Paul, U. Kamachi Mudali, B. Raj, App. Surf. Sci., 257 5088-5097 (2011).

39. I. Betova, M. Bojinov, T. Laitinen, K. Mäkelä, P. Pohjanne, T. Saario, Corr. Sci. 44, 2675-2697 (2002). 